this study and that of Michel \& Valach (BJP, June $1992,160,757-760$ ) which showed that knowledge about suicide and attitudes towards suicide prevention improved significantly in general practitioners who received a simple educational programme. A significant step in the right direction would be for psychiatric experience to become a required part of the training of all general practitioners. RuTz, W., Von KNORRING, L. \& WäLINDER, J. (1992) Long-term
effects of an educational program for general practitioners given
by the Swedish Committee for the Prevention and Treatment of
Depression. Acta Psychiatrica Scandinavica, 85, 83-88.

University of Bristol

H. G. MORGaN

Bristol BS2 8DZ

Warneford Hospital

Oxford $O X 37 J X$

K. HaWTON

\section{Seasonal affective disorder}

SIR: We read with interest the paper by Murphy and colleagues (BJP, September 1993, 163, 327-331) describing their findings on suppression of melatonin secretion in response to light in patients with seasonal affective disorder (SAD). Their paper makes reference to our earlier work (Thompson et al, 1990) and suggests that their failure to replicate our findings (that patients with SAD are supersensitive to light in winter) may be related to the fact that seven of our patients were taking benzodiazepines during the study, or because our controls differed in light sensitivity from theirs, since they found melatonin suppression values (using our method of calculation) to be $87 \%$ and $19 \%$ in our and their studies respectively.

We have recently studied the effect of daily treatment with $20 \mathrm{mg}$ temazepam for seven days on melatonin secretion and light sensitivity in seven healthy male volunteers (Allen et al, 1993) and have found no effect on either parameter. This suggests that the small doses of benzodiazepines taken by seven of our patients were unlikely to have affected our results.

There is known to be a large variation between individuals in melatonin secretion and quite possibly in light sensitivity and this no doubt explains the differences between control values in the two studies. It would therefore be unwise to directly compare the studies or to merge the control groups. The findings of Murphy et al do not therefore invalidate our study.

Our study used a control night in which subjects were exposed to dim light, the light sensitivity being expressed as the difference in melatonin between control and 'bright light' nights. Murphy et al calculated sensitivity using measurements during a one-hour baseline period (01:00 to 02:00) and during the second hour of a two-hour period of exposure to light (03:00 to 04:00). It is possible that these differences make our test more sensitive. Furthermore, Murphy et al do not address the main finding of our study as they did not repeat their tests in the summer.

We demonstrated a significant seasonal variation in light sensitivity in SAD patients, with supersensitivity compared to controls in winter and a trend to subsensitivity in summer. The summer followup is also important in partially confirming the diagnosis of SAD. Preliminary findings from a sevenyear follow-up study in our unit suggest that over $50 \%$ of DSM-III-R diagnosed winter depressives (American Psychiatric Association, 1987) remit or lose their seasonal pattern. Thus diagnostic heterogeneity of the samples may be a further cause of the differences in the findings.

We do not doubt the findings of Murphy et al, but their study differs in a number of ways to ours and cannot therefore be directly compared.

Allen, N. H. P., Smythe, P. J., Martin, N., et al (1993) The effect of temazepam on melatonin secretion and light sensitivity. Journal of Psychopharmacology (submitted).

AMERICAN PsYCHIATRIC AssocIA mon (1987) Diagnostic and Statistical Manual of Mental Disorders (3rd edn, revised) (DSM-III-R). Washington, DC: APA.

Thompson, C., Stinson, D. \& SMrth, A. (1990) Seasonal affective disorder and season-dependent abnormalities of melatonin suppression by light. Lancet, 336, 703-706.

C. THOMPSON

P. A. ChILDS

Royal South Hants Hospital

S. K. RAHEJA

Graham Road

Southampton SO9 4 PE

University of Manchester

N. H. P. Allen

Withington Hospital

Manchester

Late-onset schizophrenia versus late paraphrenia

SIR: Howard et al (BJP, September 1993, 163, 352-357) come to the conclusion that "although there are clinical similarities between cases of schizophrenia with early and late onset, there are sufficient differences to suggest that they are not phenotypically homogeneous".

The case for separation of late-onset schizophrenia, or what some of us still prefer to call late paraphrenia, 